\title{
Effects of Development of Ontogenic Resistance in Strawberry Leaves Upon Pre- and Postgermination Growth and Sporulation of Podosphaera aphanis
}

Belachew Asalf, Norwegian Institute for Agricultural and Environmental Research (Bioforsk), Plant Health and Plant Protection Division, and Department of Plant and Environmental Sciences, Norwegian University of Life Sciences, 1430 Ås, Norway; David M. Gadoury, Department of Plant Pathology, Cornell University, New York State Agricultural Experiment Station, Geneva, NY 14456; Anne Marte Tronsmo, Department of Plant and Environmental Sciences, Norwegian University of Life Sciences; Robert C. Seem, Department of Plant Pathology, Cornell University, New York State Agricultural Experiment Station; and Arne Stensvand, Bioforsk, Plant Health and Plant Protection Division

\begin{abstract}
Asalf, B., Gadoury, D. M., Tronsmo, A. M., Seem, R. C., and Stensvand, A. 2016. Effects of development of ontogenic resistance in strawberry leaves upon pre- and postgermination growth and sporulation of Podosphaera aphanis. Plant Dis. 100:72-78.

The temporal distribution and magnitude of ontogenic resistance in strawberry leaves to Podosphaera aphanis has recently been quantified. However, the degree to which the pathogen is inhibited at sequential stages of conidial germination, hyphal growth, haustoria formation, latent period, colony expansion, and sporulation on the adaxial and abaxial leaf surfaces of various strawberry cultivars remains unclear. Five developmental stages of strawberry leaves ranging from newly emerged and folded leaves to fully expanded and

dark-green leaves were inoculated with conidia of $P$. aphanis. The percentage of germinated conidia significantly declined between leaf stages 3 and 5. Postgermination growth of the pathogen was sequentially reduced in all measured responses, and the latent period was increased. Haustoria were not observed in mature leaves. The failure of the pathogen to penetrate mature leaves was a consistent feature associated with the expression of ontogenic resistance in older, fully expanded leaves.
\end{abstract}

Strawberry is a high-value fruit crop produced in both outdoor (open-field) and indoor (plastic tunnel and greenhouse) environments. Plastic tunnels have several advantages over open-field conditions such as protection of the fruit from rainfall, hail, sun scorch, and birds, and even reduces the severity and incidence of Botrytis cinerea and Colletotrichum acutatum (Xiao et al. 2001). The high economic premium associated with the appearance of berries means that there are severe economic penalties for downgrading of fruit caused by diseases, pests, or mechanical damage.

Powdery mildew caused by Podosphaera aphanis (syn. Sphaerotheca macularis) is a limiting factor in strawberry (Fragaria $\times$ ananassa Duch.) production worldwide (Maas 1998). The disease can be particularly problematic when strawberry fruit are produced in greenhouses or polythene tunnels, both of which are conducive to severe outbreaks of powdery mildew (Xiao et al. 2001). When the disease is severe, the fruit may crack and become exposed to secondary infections (Asalf 2013), and yield losses may exceed 60\% (Horn et al. 1972).

Many commercially relevant strawberry cultivars are highly susceptible to powdery mildew, and $P$. aphanis, although affected by host resistance, biological control, and cultural practices, is generally suppressed by fungicides in commercial production. Fungicide applications are sometimes delayed until symptoms are macroscopically visible. Strawberry cultivars may vary in their susceptibility to the disease. Moderate resistance to powdery mildew exhibited by some commercially relevant cultivars can mitigate but not eliminate the need to apply fungicides to suppress disease. Furthermore, cultivars that exhibit substantial resistance in mature leaves and fruit may lack resistance during the early-development stages of these organs (Asalf et al. 2014; Carisse and Bouchard 2010; Gadoury et al. 2007).

Recent studies have quantified the magnitude and temporal distribution of ontogenic (age-related) resistance to $P$. aphanis expressed in both strawberry leaves (Asalf et al. 2014; Carisse and Bouchard 2010; Gadoury et al. 2007) and fruit (Asalf et al. 2009, 2014; Carisse and Bouchard 2010). These studies focused on the macroscopic

Accepted for publication 23 June 2015.

http://dx.doi.org/10.1094/PDIS-02-15-0193-RE

(C) 2016 The American Phytopathological Society observation of signs of the pathogen in both fruit and leaf tissue for several days or weeks under greenhouse and field conditions. Although useful to describe the relative susceptibility of leaves and fruit at several phenological stages, these studies were not designed to reveal where and how the pathogen is stopped during the infection process on leaves and fruit of different ages. Likewise, the former studies did not examine the impact of ontogenic resistance on key components of epidemic progress, such as conidial germination, appressorial formation, secondary hyphal development, colony expansion, latent period, or sporulation of colonies.

Resistance to powdery mildew pathogens other than $P$. aphanis has been associated with reduced penetration, haustoria formation, hyphal growth, colony expansion, and sporulation and increased duration of the latent period (Develey-Rivière and Galiana 2007; Doster and Schnathorst 1985; Ficke et al. 2003; Fondevilla et al. 2006; Heitefuss et al. 1997; Mendgen and Deising 1993). In mature grape berries, germination and appressorium formation of conidia is not affected by fruit maturity (Ficke et al. 2003, 2004) but infection by conidia is halted at the interface of the cuticle and the epidermal cell wall (Ficke et al. 2004). Ontogenic resistance in leaves did not affect prepenetration developmental processes of Erysiphe pisi on pea plants (Fondevilla et al. 2006). More detailed studies of how age of plant organs affects each stage of infection and subsequent colonization of $P$. aphanis on strawberry may provide clues to the underlying mechanisms involved in ontogenic resistance. The objective of this study was to investigate the effect of ontogenic resistance on conidia germination, formation of haustoria, growth of hyphae, duration of the latent period, expansion of colonies, and sporulation of $P$. aphanis. Preliminary accounts of this work have been published (Asalf et al. 2010).

\section{Materials and Methods}

Plant material. Plants were propagated from runners obtained from certified strawberry plants, and were planted in $12-\mathrm{cm}$ plastic pots filled with a peat-based potting soil (P-Jord; 70\% sphagnum peat $\mathrm{H} 2$ to $\mathrm{H} 4,20 \%$ sphagnum peat $\mathrm{H} 6$ to $\mathrm{H} 8$, and $10 \%$ sand; L.O.G AS, Oslo, Norway). Plants were maintained at $18{ }^{\circ} \mathrm{C}, 80 \%$ relative humidity $(\mathrm{RH})$ and a day and night period of 16 and $8 \mathrm{~h}$, respectively, in a greenhouse. High-pressure sodium lamps provided additional daylight (balanced light) whenever natural daytime light intensity was 
below $150 \mu \mathrm{mol} / \mathrm{m}^{2} / \mathrm{s}$. The greenhouse compartment used for maintenance of plants prior to inoculations was equipped with a sulfur vaporizer to suppress powdery mildew. Five leaf developmental stages (Fig. 1) of 'Frida', 'Korona', 'Inga', and 'Senga Sengana' were identified; that is, from newly emerged, folded light green leaves (stage 1) to completely unfolded dark-green leaves (stage 5). Hereafter, leaf stages 1 to 5 will be referred to as S1, S2, S3, S4, and S5. Detached leaves were the experimental unit in all experiments. All leaves were inspected under a dissecting microscope before inoculation to confirm the absence of powdery mildew or other pathogens or pests. The four cultivars are used in commercial production in Norway.

Inoculum production, inoculation and incubation conditions. Inoculum of $P$. aphanis was produced on detached strawberry leaves of Korona and 'Earliglow' strawberry in Norway and the United States, respectively. Culture maintenance and inoculation procedures were as previously described (Asalf et al. 2012). Briefly, young, unexpanded leaves were surface sterilized by soaking the leaves in a solution of $0.5 \%$ sodium hypochlorite for $5 \mathrm{~min}$ followed by two rinses in autoclaved water. Then, the leaves were air dried, petioles were removed, and leaves were arbitrarily assigned to $9-\mathrm{cm}$ petri dishes containing water agar ( $5 \mathrm{~g} / \mathrm{liter})$. For inoculum production, the agar was amended with benzimidazole (30 mg/liter), while unamended water agar was used for leaves that were inoculated in the following experiments.

Leaves were inoculated by transferring dry conidia from 8- to 10-day-old colonies using a small paintbrush trimmed to retain a few hairs. Inoculum density was determined by transferring conidia onto glass microscope slides using the same paintbrush and estimating the number of conidia per square centimeter at $\times 400$ (Gadoury et al. 2012b). This inoculation method gave a conidia density of approximately $4.6 \times 10^{4}$ conidia/ $/ \mathrm{cm}^{2}$ (Asalf et al. 2014). Growth-chamber conditions for both inoculum production and the experiments were $20^{\circ} \mathrm{C}, 80 \% \mathrm{RH}$, and day and night periods of 16 and $8 \mathrm{~h}$, respectively.

Fixation, clearing, and preparation of leaf tissue for light microscopy. Inoculated leaves were incubated for either $24 \mathrm{~h}$ for assessments of conidial germination or $48 \mathrm{~h}$ for enumeration of hyphal tips or secondary hyphal growth. Leaf disks ( $2 \mathrm{~cm}$ in diameter) were placed with the inoculated surface facing up on filter paper in a petri dish. The disks were covered with a mixture of ethanol $(96 \%)$ and glacial acetic acid (100\%) (1:1 [vol/vol]) overnight to clear the tissue. The leaflets were then stored in lactoglycerol (lactic acid/glycerol/water [1:1:1]) until stained and mounted on glass slides. This method was slightly modified from (Carver et al. 1991). To stain the fungal structures, the cleared leaves were transferred to microscope glass slides and stained with either aniline blue or trypan blue (Feechan et al. 2011) for experiments completed in Norway, or with Coomassie brilliant blue for experiments completed in New York.

Preparing samples for light microscopy and scanning electron microscopy. Histological studies were conducted upon three emergent (susceptible) or three fully expanded (resistant) leaves of Earliglow to detect the formation of haustoria on both the adaxial and abaxial surface of the leaves. Leaves were surface sterilized as previously described (Asalf et al. 2012) and leaflets were placed on water agar in a $9-\mathrm{cm}$ petri plate with the adaxial or abaxial surface uppermost, and were then inoculated and incubated for 5 days, as described above. Thus, replicates consisted of three leaflets in one petri plate, and treatments (young versus old and adaxial versus abaxial) were replicated three times. On day 5 after inoculation, a single 5-mm disk was cut from each leaflet, fixed in formalinacetic acid-alcohol for $24 \mathrm{~h}$, rinsed twice in $50 \%$ ethanol for $2 \mathrm{~h}$, and dehydrated in an ethanol-tertiary butanol (TBA) series (Ruzin 1999), as follows: TBAII (50\% ethanol, 20\% TBA, and 30\% water) overnight, TBA III (50\% ethanol, $35 \%$ TBA, and $15 \%$ water) for $3 \mathrm{~h}$, TBA IV (50\% ethanol and 50\% TBA) for $3 \mathrm{~h}$, TBA V (25\% pure ethanol and $75 \%$ TBA) for $3 \mathrm{~h}, 100 \%$ TBA overnight, followed by two changes of $100 \%$ TBA for $2 \mathrm{~h}$ each. After these dehydration processes, the leaf disks were infiltrated with paraffin (two leaf disks for cross and one for paradermal sections), and cross sectioned at a thickness of $10 \mu \mathrm{m}$ on a rotary microtome, stained with Safranin O and Fast Green FCF, and observed microscopically, as described previously (Gadoury et al. 2010). A slide contained between 16 and 20 5-mm-long cross sections. All sections of a leaf disk were assessed for the presence of haustoria in the epidermal layer of the leaf disks.

Emergent and fully expanded leaves of "Earliglow" were also inoculated with dry inoculum and processed for scanning electron microscopy (SEM) observation at 2, 12, 24, and $90 \mathrm{~h}$ postinoculation, as described previously (Gadoury et al. 2010). Leaflet pieces (approximately $4 \mathrm{~mm}^{2}$ ) were cut, prefixed in $3 \%$ glutaraldehyde in a buffered phosphate solution for $2 \mathrm{~h}$, and thereafter fixed in $2 \%$ osmium tetroxide for $50 \mathrm{~min}$ followed by two rinses in phosphate buffer concentration for $1 \mathrm{~h}$ each. After fixation, samples were dehydrated in an ethanol series $(10,20,30,40,50,70,80,95$, and $100 \%$ ), dried in a critical point drier, and sputter coated with gold; then, colony growth was observed using a Hitachi S-530 scanning electron microscope.

Effect of leaf age on conidial germination and hyphal growth. Five leaf stages representing different ages (S1 to S5) and, thus, different levels of ontogenic resistance were collected from disease-free plants of Frida, Korona, Inga, and Senga Sengana (Fig. 1). Leaves were surface sterilized, inoculated with dry inoculum, and incubated as described above (Asalf et al. 2012). Within an age class, leaflets were arbitrarily distributed among replications and placed in 9-cm petri dishes containing $0.5 \%$ water agar. After incubation, leaf disks ( $2 \mathrm{~cm}$ in diameter) were excised from the inoculated area of the leaflets and cleared and stained for light microscopy, as described above. The experiment included three replications for each of the four cultivars and each leaf growth stage. The experiment was repeated twice. At $24 \mathrm{~h}$ after inoculation (hai), the disks were examined microscopically and germination or lack thereof was assessed for 100 conidia/disk. Conidia bearing a germ tube with a length greater than one-half the diameter of the conidium were counted as germinated. The germination experiment was repeated twice more with the following modifications: only the highly susceptible cultivar Korona was used, and germination on stage 1 leaves was compared with germination on stage 5 leaves (Fig. 1).

Formation of secondary hyphae by germinated conidia was considered evidence of successful penetration and establishment by $P$. aphanis. The hyphae of $P$. aphanis have a tapering tip that branches subapically, with each branch having a tip of its own. For the purpose of this experiment, hyphal growth, specifically hyphal branching, was operationally defined as the number of hyphal tips developed from a germinated conidium 48 hai. It was necessary to produce and then select nonoverlapping colonies to count the hyphal tips unambiguously. Therefore, leaflets were inoculated with a relatively low conidial density (approximately $10^{3}$ conidia $/ \mathrm{cm}^{2}$ ). After $48 \mathrm{~h}$ of incubation, leaf disks $2 \mathrm{~cm}$ in diameter were excised from the inoculated area of the leaflets and cleared as described above.

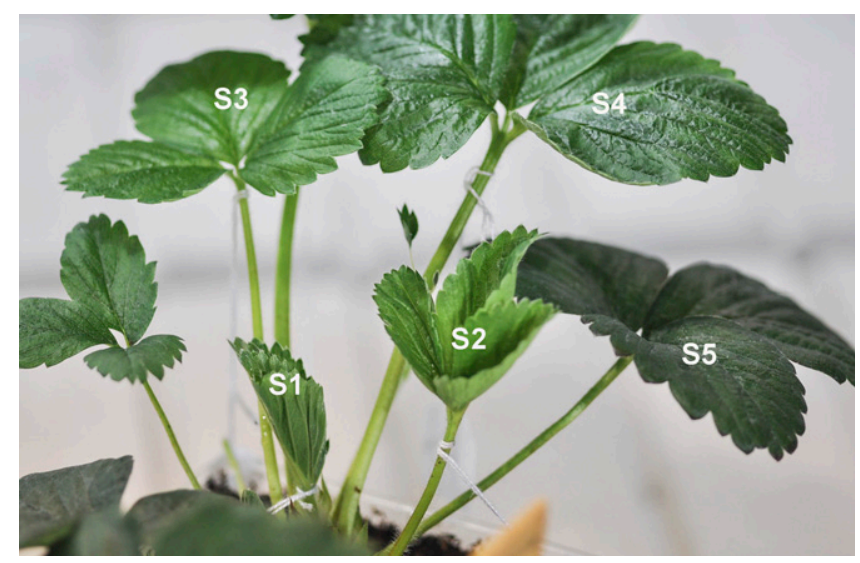

Fig. 1. Strawberry leaf developmental stages (S1 to S5) selected for the ontogenic resistance study. 
The number of hyphal tips was determined for 10 distinct colonies per replicate for each of the five leaf growth stages of the four cultivars. The experiment included three replicates and was repeated twice.

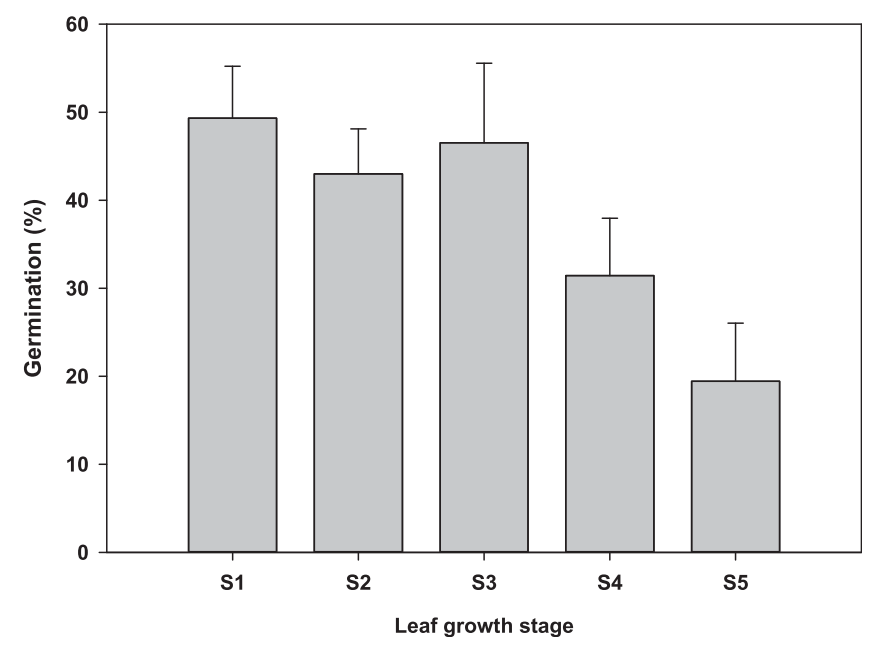

Fig. 2. Percent germinated conidia of Podosphaera aphanis inoculated on leaves of five different growth stages (S1 to S5) of four cultivars recorded $24 \mathrm{~h}$ after inoculation. Data from Korona, Senga Sengana, and Frida were pooled. Error bars indicate one standard error of the mean.

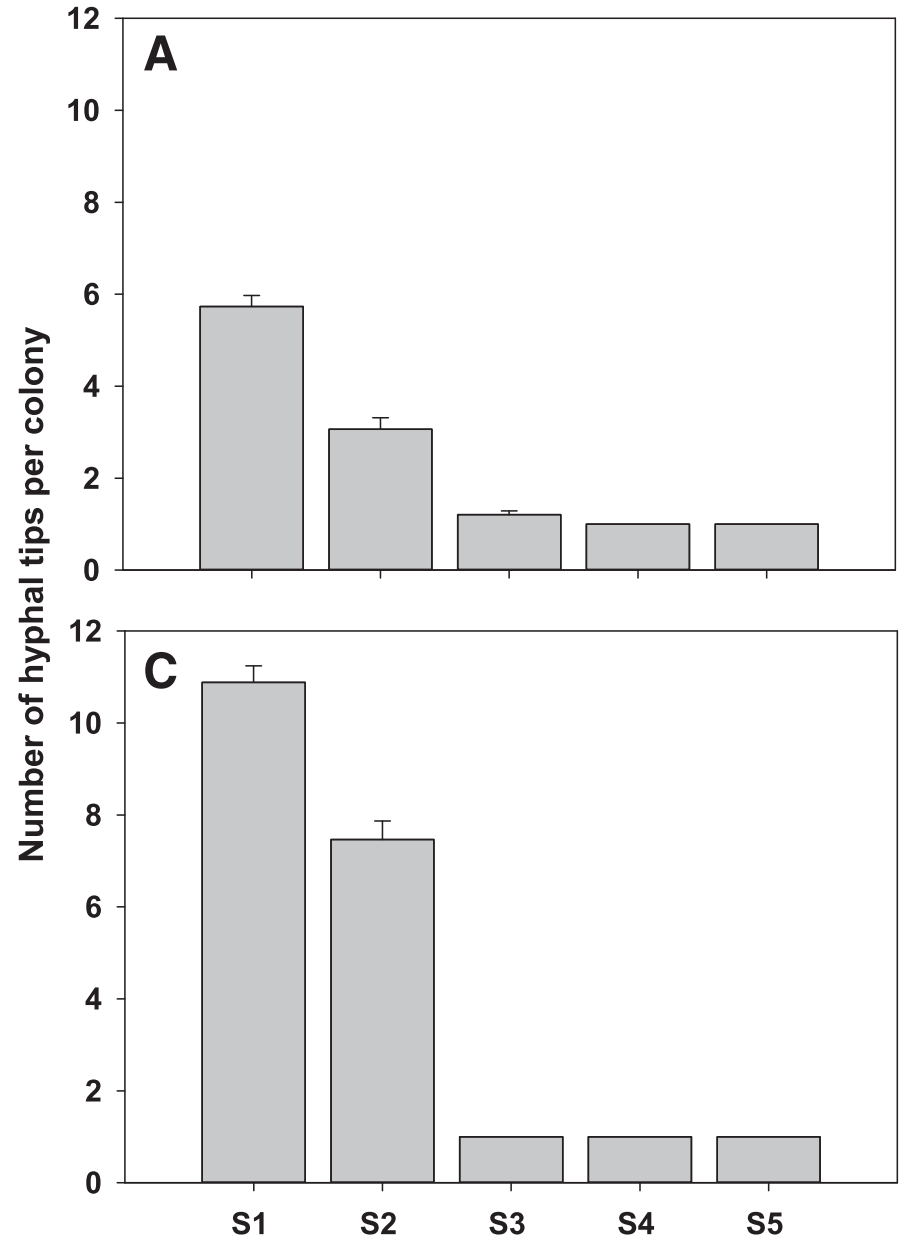

Effect of leaf age on latent period and colony expansion. Strawberry cultivars, leaf stages, and agar media used in these experiments were the same as described above for the conidial germination and hyphal growth experiments. Latent period is defined here as the number of days from inoculation to first occurrence of sporulation on each of the inoculated leaflets. Initiation of sporulation of $P$. aphanis was assessed daily beginning 3 days after inoculation (dai) with the aid of a dissecting microscope. Sporulation is defined here as the percentage of colonized leaf area bearing conidiophores with a conidia. Assessments were made daily up to 10 dai on each of the five leaf growth stages of the four cultivars (Fig. 1). The leaflet area colonized by $P$. aphanis was estimated 10 dai in all cultivars. Because the area of the leaflets among leaf ages varies, estimation of the colony expansion or percentage of leaf area covered by the colony was misleading. To avoid variation in leaflet size, the field of view in the dissecting microscope (LEICA MZ125) was adjusted to include the leaflet area bearing colonies, and the actual leaf area covered by each colony or colonies was then estimated by calculating the area of the field of view for each magnification used. The diameter of the circular field of view assessed was based upon the variable objective magnification. The field diameter in millimeters was used to calculate the area of the circular field, and the proportion of this area covered by powdery mildew colonies was visually estimated. Where two or more distinct colonies occurred on a leaflet, the area of each colony was determined and the areas were summed to yield the total area covered by powdery mildew for an assessed leaflet. Each experiment included three replications of each leaf stage and cultivar. The experiments were repeated three times.
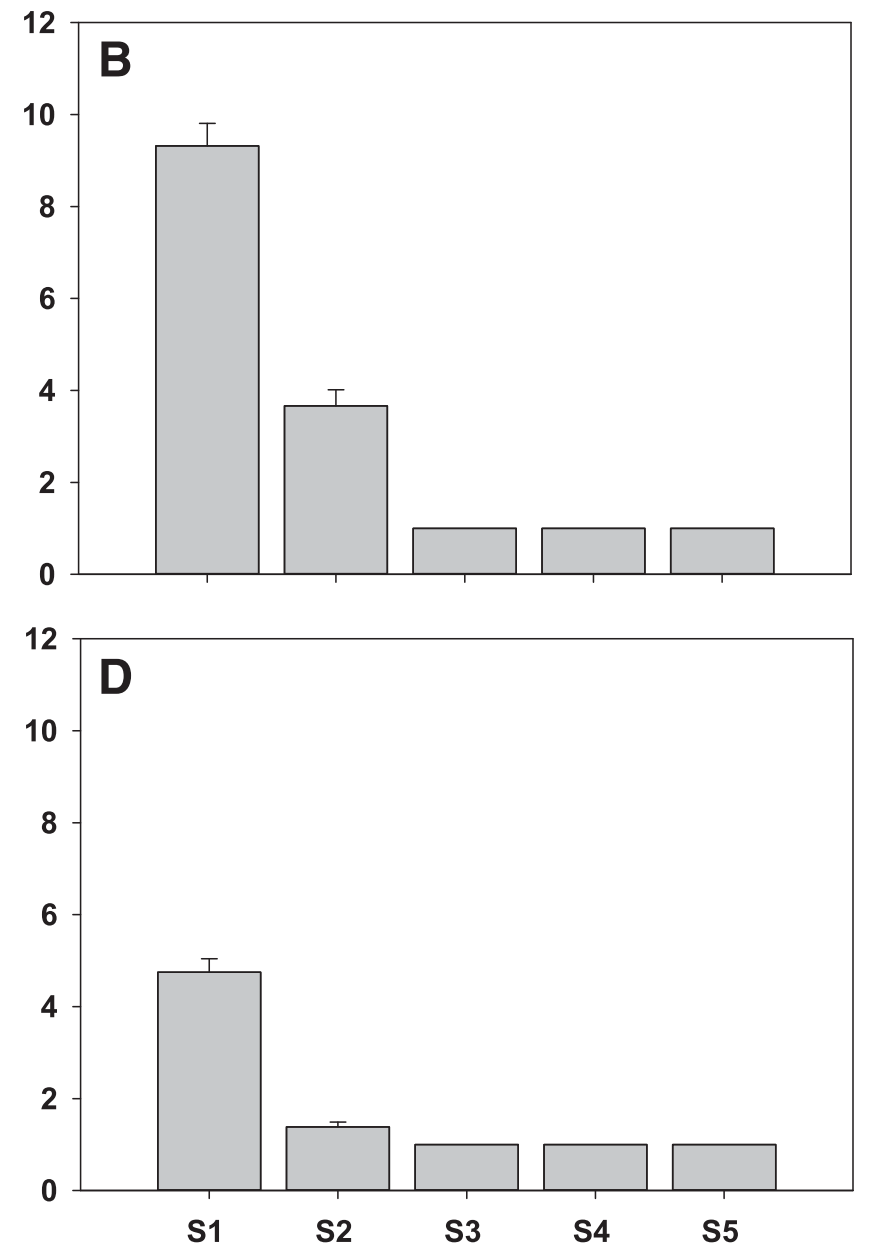

Leaf growth stages

Fig. 3. Number of hyphal tips per colony $48 \mathrm{~h}$ after inoculation of Podosphaera aphanis on leaf stages 1 to 5 (S1 to S5) of four strawberry cultivars: A, Frida; B, Korona; C, Inga; and $D$, Senga Sengana. Error bars indicate one standard error of the mean. 
Data analysis. After testing of the data for normal distribution and homogeneity of variance, data that violate the assumptions of parametric statistical tests were transformed. Data for the count of hyphal tips per colony were transformed using the square root transformation, whereas the colony expansion and sporulation data were transformed using natural logarithms. The proportion of germinated conidia were transformed using the arcsine transformation before analysis. Interactions between cultivars and leaf age were also analyzed. Although analyses were conducted on the transformed values, data reported in graphs, tables, and the text are presented in the original units of measure. Analysis of variance was used to determine significance of effects of cultivar and leaf age on infection processes using Minitab, version 16 (Minitab 2010). When the effect of the treatment was significant $(P<0.05)$, comparison of means were performed with Tukey's pairwise test at $5 \%$ level of significance.

\section{Results}

Effect of leaf age on conidial germination, haustoria formation, and hyphal growth. Germination of conidia upon equivalent leaf stages was not significantly $(P=0.10)$ affected by cultivar, and data from four cultivars of the first experimental series on germination were therefore pooled for analysis (Fig. 2). Conidial germination was not significantly affected by leaf age at leaf stages 1,2 , or 3 but declined significantly $(P=0.016)$ by $15 \%$ between stages 3 and 4 and by $12 \%$ between stages 4 and 5 (Fig. 2). When the experiments were repeated using only S1 and S5 leaves of Korona, germination decreased significantly $(P=0.001)$ from $81.8 \%$ (standard error $[\mathrm{SE}]=2.47 \%$ ) on stage 1 leaves to $21.0 \%$ $(\mathrm{SE}=2.99 \%)$ on stage 5 leaves.

There was a significant cultivar-leaf age interaction on number of hyphal tips per colony $(P=0.001)$. The number of hyphal tips per colony was significantly reduced $(P<0.001)$ as leaf age increased, particularly between leaf stages 1 and 3 (Fig. 3). Hyphal growth was most prolific on $\mathrm{S} 1$ leaves followed by $\mathrm{S} 2$ leaves in all cultivars (Fig. 4A and B). The mean number of hyphal tips per colony 48 hai on S1, S2, and S3 leaves of all cultivars was 7.67, 3.90, and 1.05, respectively. Hyphal branching of germinated conidia at 48 hai was not observed on S4 and S5 leaves of any cultivar (Fig. 3). The number of hyphal tips on S1 and S2 leaves was significantly lowest on Senga Sengana (Fig. 3).

SEM and light microscopic observations of conidia germination, hyphal branching, and haustoria formation on both the upper and lower surfaces of S1 and S5 leaves of Earliglow in the United States showed results similar to that observed on leaves of the same age class of the cultivars in Norway. The following results were from Earliglow. Germination had not yet begun at 2 hai on either S1 or S5 leaves. By 12 hai, germinated conidia with primary germ tubes formed cross walls, and appressoria were abundant on S1 leaves. In $\mathrm{S} 1$ leaves, germ tubes differentiated and colonies expanded rapidly (Fig. 4C). In contrast, conidia failed to develop beyond a germ tube on S5 leaves even 90 hai (Fig. 4D). Haustoria formation was clearly observed on the upper surface of the leaf after leaf clearing but difficult to observe on the lower surface of the leaf. Cross sections prepared from S1 leaves revealed haustoria inside the epidermal cells subtending appressoria within the overlying colony 5 dai (Fig. 4E). However, haustoria were observed in abundance in paradermal sections of both the abaxial and adaxial surfaces of $\mathrm{S} 1$ leaves. Haustoria were never found in the cross section or the paradermal sections prepared from the abaxial and adaxial surfaces of S5 leaves.

Effect of leaf age on latency and colony expansion. The duration of latency (the period from inoculation to first sporulation) increased significantly with leaf maturity $(P<0.001$; Table 1$)$. In all cultivars, the latent period was shortest (4 to 6 days) on S1 leaves, and increased with leaf age (Table 1). There was an interaction between cultivar and leaf age in the latent period of $P$. aphanis (Table 1). The latent period of S1 leaves of Senga Sengana was significantly longer $(P=0.03)$ compared with the other cultivars of the same growth stage. On S3 leaves of Inga and Senga Sengana, and S4 and S5 leaves of all cultivars, no sporulation had occurred by 10 dai (Table 1 ).
For all cultivars, the colony expansion was greatest on $\mathrm{S} 1$ and $\mathrm{S} 2$ leaves (Fig. 5). In all cultivars, sporulation was highest on S1 leaves (Fig. 6). There was no hyphal development beyond germ tubes of conidia on S4 and S5 leaves, except for Korona, where trace levels of hyphal growth were found on one S5 leaflet (Fig. 5). Sporulation declined with increase in leaf age, and showed a declining trend similar to that observed for colony expansion (Fig. 6). Both colony expansion and sporulation were reduced in Senga Sengana compared with other cultivars of the same leaf age. The fungus grew profusely on $\mathrm{S} 1$ leaves, and there was no obvious cellular damage or necrosis in the leaf tissue. In S2 leaves of Korona and Senga Sengana, colony expansion was significantly reduced, but in Frida and Inga, colony expansion did not differ from S1 leaves. In S3 leaves of Korona, there was clearly visible cell death or dark-brown discoloration beneath the hyphae.

\section{Discussion}

As the strawberry leaves expanded and unfolded, ontogenic resistance suppressed $P$. aphanis in a comprehensive fashion across several measures of pathogen establishment and growth. Both prepenetration (reduced germination) and postpenetration (reduced hyphal development, haustorial formation, increased period of latency, and reduced sporulation) effects were observed. In the oldest (S5) leaves, all the pre- and postinfection processes of the fungus, including germination, were inhibited. The absence of secondary hyphal growth on the oldest leaves (S4 and S5) was largely a direct consequence of the failure of the pathogen to successfully establish (i.e., there were few successful nascent colonies from which secondary growth could occur). Although initial establishment was observed on S3 leaves, ontogenic resistance limited further colony development. Resistance mechanisms acting after penetration and haustoria formation have involved degraded function of haustoria in E. pisi (Prats et al. 2007). Although we did not assess function of haustoria, they were completely absent in S5 leaves.

Earlier reports had shown that ontogenic resistance could be detected at very early stages of leaf development (Carisse and Bouchard 2010; Gadoury et al. 2007). In the present study, by the time highly folded
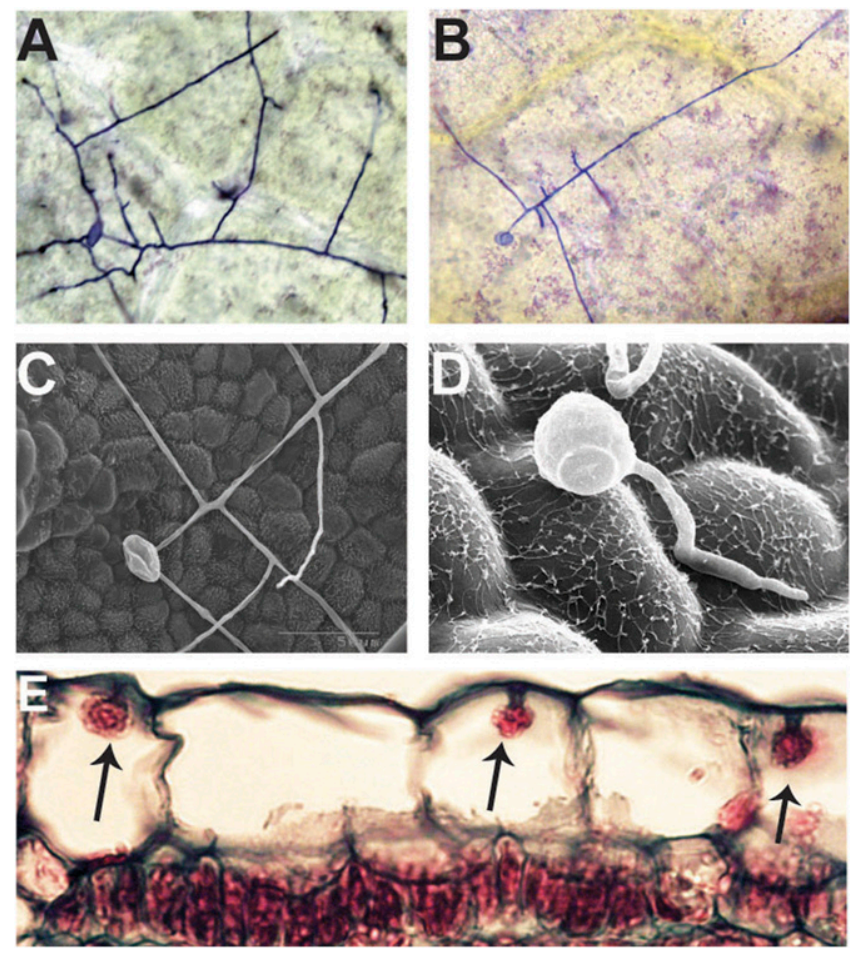

Fig. 4. Development of Podosphaera aphanis on leaves of strawberry. Hyphal growth on $\mathbf{A}$, stage 1 and $\mathbf{B}$, stage 2 leaves of Korona $48 \mathrm{~h}$ after inoculation. Germinated conidia on $\mathbf{C}$, stage 1 and $\mathbf{D}$, stage 5 leaves of Earliglow $90 \mathrm{~h}$ after inoculation. $\mathbf{E}$, Cross section of stage 1 leaf of Earliglow showing fully developed haustoria 5 days after inoculation. 
strawberry leaflets (S1 and S2) had begun to unfurl (S3), hyphal branching and sporulation was reduced in all cultivars. Although incompletely effective in suppressing the pathogen, the impact of ontogenic resistance could be seen in some responses (e.g., number of hyphal tips) at the earliest stages of host development (Fig. 3). P. aphanis was only able to colonize substantial portions of leaflets at the S1 and S2 stages, before ontogenic resistance was strongly expressed. As leaves advanced in maturity, additional measures of establishment and growth (i.e., germination) were affected. Leaf development beyond S1 is characterized by expansion of the leaf,

Table 1. Increase in latent period of Podosphaera aphanis with increase in strawberry leaf age

\begin{tabular}{lcccc}
\hline & \multicolumn{4}{c}{ Length of latent periods for four cultivars ${ }^{\mathbf{z}}$} \\
\cline { 2 - 5 } GS & Frida & Korona & Inga & Senga Sengana \\
\hline S1 & $4.1 \pm 0.11$ a A & $4.1 \pm 0.11$ a A & $4.7 \pm 0.17$ a A & $5.8 \pm 0.28$ a B \\
S2 & $4.9 \pm 0.2$ b A & $5.4 \pm 0.24$ b AB & $5.9 \pm 0.2$ b BC & $6.3 \pm 0.25$ a C \\
S3 & $6.8 \pm 0.28$ c A & $6.5 \pm 0.19$ c A & - & - \\
S4 & - & - & - & - \\
S5 & - & - & - & - \\
\hline
\end{tabular}

${ }^{\mathrm{z}}$ Mean separation. Lowercase letters within the same columns (the same cultivar of different leaf growth stages [GS]) and uppercase letters across the same row (the same GS of different cultivars) followed by the same letter were not statistically different $(P>0.05)$. Values are mean number of days from inoculation to the formation of the first conidia visible in a dissecting microscope; - indicates absence of successful infections during the experimental period. primarily through expansion of the epidermal cells rather than differentiation of tissues. Of the four cultivars examined, Senga Sengana possessed the highest level of innate resistance to powdery mildew (Figs. 3, 5, and 6) and, coincidentally, also exhibited the highest rates of leaf expansion (data not shown). There was a rapid movement form a highly susceptible (S1) to more or less resistant (S2) leaf stage. Given the substantial change in ontogenic resistance between the $\mathrm{S} 1$ and S2 stages, the rapid movement of emergent leaves out of the highly susceptible S1 stage to S2 and later stages could be one indicator of a phenotype with potentially higher levels of innate resistance to powdery mildew. The long latent period of the pathogen on S1 leaves of Senga Sengana indicated that the young leaves have some resistance to the pathogen, and the cultivar potentially could be used for breeding to powdery mildew resistance.

Development of ontogenic resistance to $P$. aphanis in strawberry leaves produced responses similar to those reported in other powdery mildew pathosystems. The sequential inhibition of the infection processes of powdery mildews in maturing plant tissues or organs has been investigated in grapevine (Doster and Schnathorst 1985; Ficke et al. 2002), peach (Weinhold and English 1964), oak (Edwards and Ayres 1981), and cashew (Sijaona et al. 2001). The failure to penetrate the epidermal cell wall and develop functional haustoria was the principal response noted in ontogenic resistance against $E$. necator on maturing grape leaves (Doster and Schnathorst 1985) and grape berries (Ficke et al. 2002). Our observation of reduced conidial germination on S5 leaves of Korona is a less commonly observed manifestation of ontogenic resistance to powdery mildews. For example, conidia of $E$. necator germinate equally well on young and old grape berries
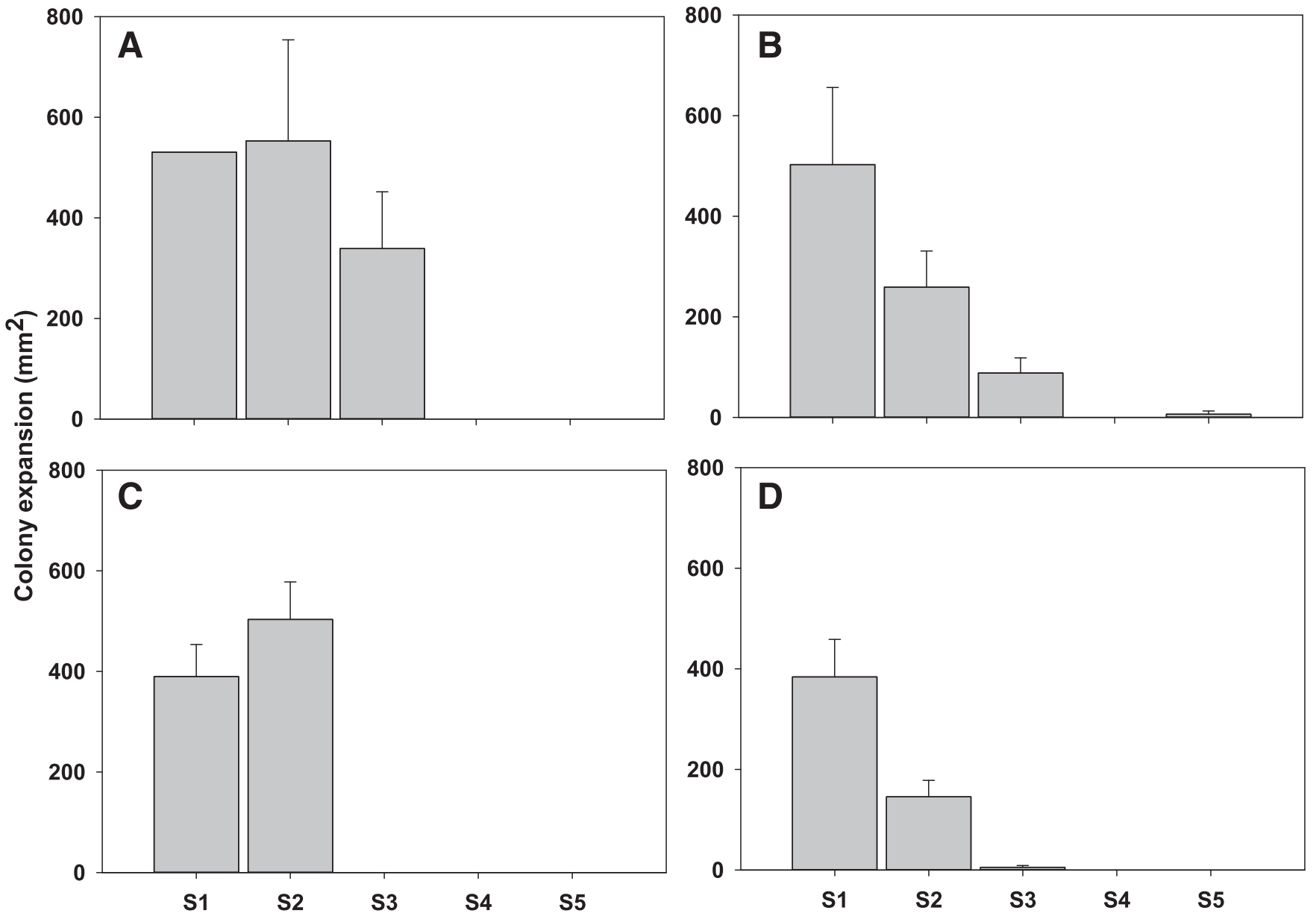

Leaf growth stages

Fig. 5. Colony expansion of Podosphaera aphanis on different leaf growth stages (S1 to S5) of four strawberry cultivars: A, Frida; B, Korona; C, Inga; and D, Senga Sengana 10 days after inoculation. Error bars indicate one standard error of the mean. 

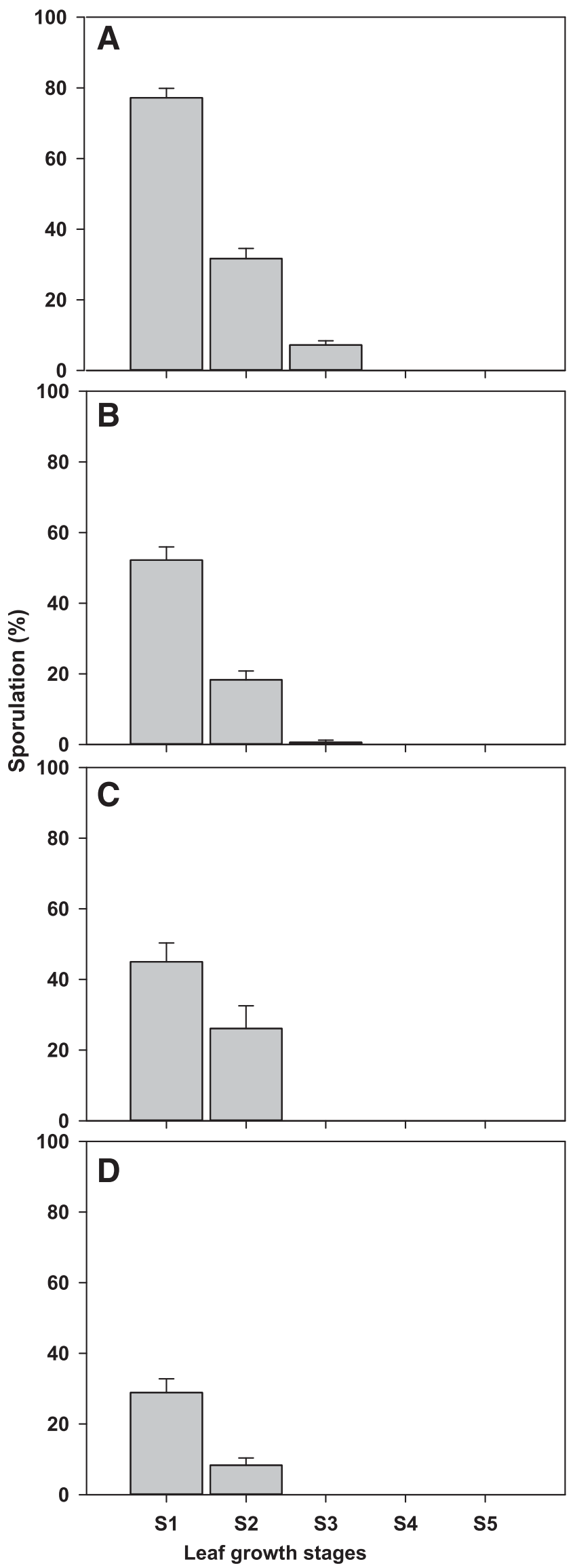

Fig. 6. Sporulation of Podosphaera aphanis on different leaf growth stages (S1 to S5) of four strawberry cultivars: A, Frida; B, Korona; C, Inga; and D, Senga Sengana 10 days after inoculation. Error bars indicate one standard error of the mean.
(Ficke et al. 2002). Penetration resistance (Thordal-Christensen 2003), particularly in some powdery mildew pathosystems (Feechan et al. 2011; Zeyen et al. 2002), has been associated with constitutive plant features such as waxes and cuticle thickness (Peries 1962; Tsuba et al. 2002; Weinhold and English 1964), accumulation of phenolic compounds, and papillae formation (Glazebrook 2005; Heitefuss et al. 1997; Hukkanen et al. 2007; Kus et al. 2002; von Röpenack et al. 1998; Zeyen et al. 2002). However, none of the foregoing was associated with penetration resistance to E. necator in grape berries (Ficke et al. 2004), where penetration resistance appeared to involve an inducible response (Gadoury et al. 2012a). Although it is well known that the cuticle of strawberry leaves increases in thickness during development as leaves mature (Jhooty and McKeen 1965; Peries 1962), and that they accumulate various pathogenesis-related compounds, including salicylic acid, as they mature (Hukkanen et al. 2007), elucidation of the mechanisms underlying ontogenic resistance to $P$. aphanis will require further research.

Our results illustrate how the rapid decline in susceptibility of strawberry leaves results in the selective establishment and growth of the pathogen on the youngest and most susceptible tissues. On S1 leaves of all cultivars, approximately $50 \%$ of all conidia germinated. The pathogen subsequently penetrated the epidermis and established functional haustoria. Abundant secondary hyphae developed thereafter; colonies expanded rapidly, and sporulation occurred within 4 to 6 dai. This is in agreement with previous indications (Asalf et al. 2014; Carisse and Bouchard 2010) that severe infection of strawberry leaves in all cultivars is a consequence of infection at the earliest stages of leaf development. Although differing in their innate level of susceptibility to infection, even the most susceptible cultivars strongly expressed ontogenic resistance in S3 and older leaves. Thus, innate susceptibility or environmental favorability could moderate a foliar infection once established but it is pathogen establishment itself at the earliest stage of leaf development that is the primary requirement. Later, it is what makes any further development of foliar powdery mildew possible or impossible. Therefore, management of $P$. aphanis is likely to be improved if growers can effectively suppress pathogen development on the tissues most at risk of infection: the very youngest leaves on strawberry plants. Factors likely to be influential on overall risk of infection would include (i) the rate at which new leaves are produced, (ii) the accessibility of the newly produced leaves to fungicide applications, and (iii) the propensity of fungicide residues to move systemically or by vapor activity to provide protection to newly formed leaves.

\section{Acknowledgments}

This work was supported by the Research Council of Norway, the Norwegian University of Life Sciences, and Norwegian Institute for Agricultural and Environmental Research (Bioforsk). We thank A. Dobson (Bioforsk) and M. J. Welser (Cornell University) for technical assistance.

\section{Literature Cited}

Asalf, B. 2013. Strawberry powdery mildew: pathogen biology, ecology and components of disease resistance in the host. PhD thesis, Norwegian University of Life Sciences, Ås, Norway.

Asalf, B., Gadoury, D. M., Tronsmo, A. M., Seem, R. C., Dobson, A., Peres, N. and Stensvand, A. 2014. Ontogenic resistance of leaves and fruit, and how leaf folding influences the distribution of powdery mildew on strawberry plants colonized by Podosphaera aphanis. Phytopathology 104:954-963.

Asalf, B., Stensvand, A., Gadoury, D. M., Seem, R. C., Dobson, A., and Tronsmo, A. M. 2009. Ontogenic resistance to powdery mildew in strawberry fruits. In: Proc. 10th Int. Epidemiol. Workshop. Cornell University, Ithaca, NY.

Asalf, B., Stensvand, A., Gadoury, D. M., Seem, R. C., and Tronsmo, A. M. 2010. Effect of leaf age on primary infection and development of colonies of strawberry powdery mildew. (Abstr.) Phytopathology 100:S8.

Asalf, B., Trandem, N., Stensvand, A., Wekesa, V. W., de Moraes, G. J., and Klingen, I. 2012. Influence of sulfur, powdery mildew, and the predatory mite Phytoseiulus persimilis on two-spotted spider mite in strawberry. Biol. Control 61:121-127.

Carisse, O., and Bouchard, J. 2010. Age-related susceptibility of strawberry leaves and berries to infection by Podosphaera aphanis. Crop Prot. 29: 969-978.

Carver, T., Robbins, M., and Zeyen, R. 1991. Effects of two PAL inhibitors on the susceptibility and localized autofluorescent host cell responses of oat 
leaves attacked by Erysiphe graminis DC. Physiol. Mol. Plant Pathol. 39: 269-287.

Develey-Rivière, M. P., and Galiana, E. 2007. Resistance to pathogens and host developmental stage: A multifaceted relationship within the plant kingdom. New Phytol. 175:405-416.

Doster, M., and Schnathorst, W. 1985. Effects of leaf maturity and cultivar resistance on development of the powdery mildew fungus on grapevines. Phytopathology 75:318-321.

Edwards, M. C., and Ayres, P. G. 1981. Cell death and cell wall papillae in the resistance of oak species to powdery mildew disease. New Phytol. 89:411-418.

Feechan, A., Kabbara, S., and Dry, I. B. 2011. Mechanisms of powdery mildew resistance in the Vitaceae family. Mol. Plant Pathol. 12:263-274.

Ficke, A., Gadoury, D. M., and Seem, R. C. 2002. Ontogenic resistance and plant disease management: A case study of grape powdery mildew. Phytopathology 92:671-675.

Ficke, A., Gadoury, D. M., Seem, R. C., and Dry, I. B. 2003. Effects of ontogenic resistance upon establishment and growth of Uncinula necator on grape berries. Phytopathology 93:556-563.

Ficke, A., Gadoury, D. M., Seem, R. C., Godfrey, D., and Dry, I. B. 2004. Host barriers and responses to Uncinula necator in developing grape berries. Phytopathology 94:438-445.

Fondevilla, S., Carver, T., Moreno, M., and Rubiales, D. 2006. Macroscopic and histological characterisation of genes er1 and er2 for powdery mildew resistance in pea. Eur. J. Plant Pathol. 115:309-321.

Gadoury, D. M., Asalf, B., Heidenreich, M. C., Herrero, M. L., Welser, M. J., Seem, R. C., Tronsmo, A. M., and Stensvand, A. 2010. Initiation, development, and survival of cleistothecia of Podosphaera aphanis and their role in the epidemiology of strawberry powdery mildew. Phytopathology 100:246-251.

Gadoury, D. M., Cadle-Davidson, L., Wilcox, W. F., Dry, I. B., Seem, R. C., and Milgroom, M. G. 2012a. Grapevine powdery mildew (Erysiphe necator): A fascinating system for the study of the biology, ecology, and epidemiology of an obligate biotroph. Mol. Plant Pathol. 13:1-16.

Gadoury, D. M., Stensvand, A., Seem, R. C., and Heidenreich, C. 2007. Ontogenic resistance of leaves, leaf folding and the distribution of mildew colonies in strawberry powdery mildew (Podosphaera macularis). (Abstr.) Phytopathology 97:S38.

Gadoury, D. M., Wakefield, L. M., Cadle-Davidson, L., Dry, I. B., and Seem, R. C. 2012 b. Effects of prior vegetative growth, inoculum density, light, and mating on conidiation of Erysiphe necator. Phytopathology 102:65-72.

Glazebrook, J. 2005. Contrasting mechanisms of defense against biotrophic and necrotrophic pathogens. Annu. Rev. Phytopathol. 43:205-227.

Heitefuss, R., Ebrahim-Nesbat, F., Ordonez, M., and Schorn-Kasten, K. 1997. Investigations on adult plant resistance of barley against Erysiphe graminis f. sp. hordei. J. Phytopathol. 145:177-184.

Horn, N. L., Burnside, K. R., and Carver, R. B. 1972. Powdery mildew of strawberry. Plant Dis. Rep. 56:368.
Hukkanen, A. T., Kokko, H. I., Buchala, A. J., McDougall, G. J., Stewart, D. Kärenlampi, S. O., and Karjalainen, R. O. 2007. Benzothiadiazole induces the accumulation of phenolics and improves resistance to powdery mildew in strawberries. J. Agric. Food Chem. 55:1862-1870.

Jhooty, J., and McKeen, W. 1965. The influence of host leaves on germination of the asexual spores of Sphaerotheca macularis (Wallr. ex. Fr.) Cooke. Can. J. Microbiol. 11:539-545.

Kus, J. V., Zaton, K., Sarkar, R., and Cameron, R. K. 2002. Age-related resistance in Arabidopsis is a developmentally regulated defense response to Pseudomonas syringae. Plant Cell 14:479-490.

Maas, J. L. 1998. Compendium of Strawberry Diseases, 2nd ed. American Phytopathological Society, St. Paul, MN.

Mendgen, K., and Deising, H. 1993. Infection structures of fungal plant pathogens-A cytological and physiological evaluation. New Phytol. 124: 193-213.

Minitab. 2010. Minitab 16 Statistical Software 2003, Minitab for Windows Minitab Inc., State College, PA.

Peries, O. S. 1962. Studies on strawberry mildew, caused by Sphaerotheca macularis (Wallr. ex Fries) Jaczewski. II. Host-parasite relationships on foliage of strawberry varieties. Ann. Appl. Biol. 50:225-233.

Prats, E., Llamas, M. J., and Rubiales, D. 2007. Characterization of resistance mechanisms to Erysiphe pisi in Medicago truncatula. Phytopathology 97: 1049-1053.

Ruzin, S. 1999. Plant Microtechnique and Microscopy. Oxford University Press, New York.

Sijaona, M., Clewer, A., Maddison, A., and Mansfield, J. 2001. Comparative analysis of powdery mildew development on leaves, seedlings and flower panicles of different genotypes of cashew. Plant Pathol. 50:234-243.

Thordal-Christensen, H. 2003. Fresh insights into processes of nonhost resistance. Curr. Opin. Plant Biol. 6:351-357.

Tsuba, M., Katagiri, C., Takeuchi, Y., Takada, Y., and Yamaoka, N. 2002. Chemical factors of the leaf surface involved in the morphogenesis of Blumeria graminis. Physiol. Mol. Plant Pathol. 60:51-57.

von Röpenack, E., Parr, A., and Schulze-Lefert, P. 1998. Structural analyses and dynamics of soluble and cell wall-bound phenolics in a broad spectrum resistance to the powdery mildew fungus in barley. J. Biol. Chem. 273: 9013-9022.

Weinhold, A. R., and English, H. 1964. Significance of morphological barriers and osmotic pressure in resistance of mature peach leaves to powdery mildew. Phytopathology 54:1409-1414.

Xiao, C. L., Chandler, C. K., Price, J. F., Duval, J. R., Mertely, J. C., and Legard, D. E 2001. Comparison of epidemics of Botrytis fruit rot and powdery mildew of strawberry in large plastic tunnel and field production systems. Plant Dis. 85:901-909.

Zeyen, R., Carver, T., and Lyngkjaer, M. F. 2002. Epidermal cell papillae. Pages 107-125 in: The Powdery Mildews: A Comprehensive Treaties. R. R. Belanger, W. R. Bushnell, A. J. Dik, and T. L. W. Carver, eds. American Phytopathological Society, St. Paul, MN. 